This item was submitted to Loughborough's Research Repository by the author.

Items in Figshare are protected by copyright, with all rights reserved, unless otherwise indicated.

\title{
Improving competitive positioning through complementary organisational
} resources

PLEASE CITE THE PUBLISHED VERSION

http://dx.doi.org/10.1108/02635571311324151

PUBLISHER

(C) Emerald Group Publishing Limited

VERSION

AM (Accepted Manuscript)

LICENCE

CC BY-NC-ND 4.0

REPOSITORY RECORD

Doherty, Neil, and Mark J. Terry. 2019. "Improving Competitive Positioning Through Complementary Organisational Resources”. figshare. https://hdl.handle.net/2134/13420. 
This item was submitted to Loughborough's Institutional Repository (https://dspace.lboro.ac.uk/) by the author and is made available under the following Creative Commons Licence conditions.

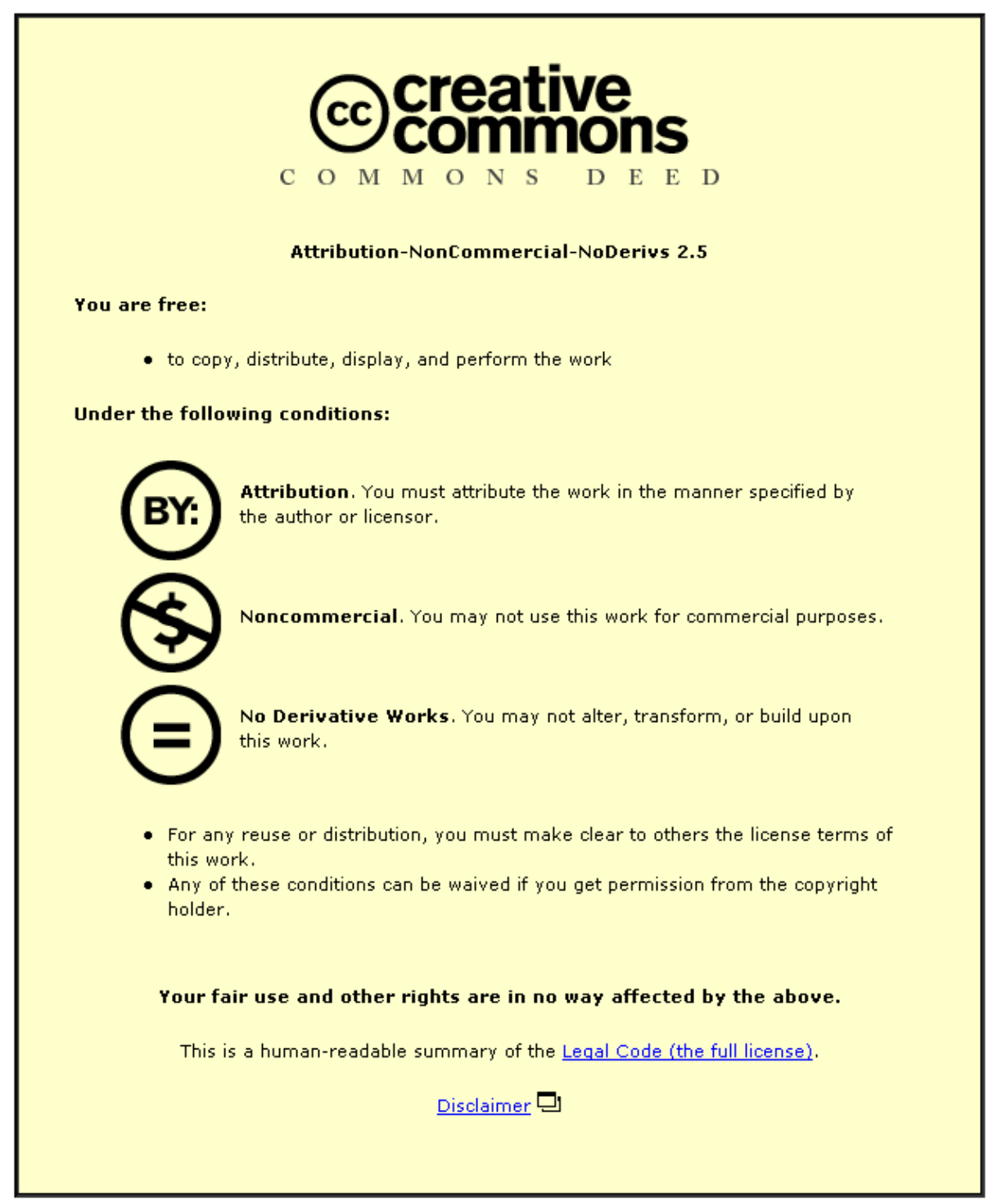

For the full text of this licence, please go to: http://creativecommons.org/licenses/by-nc-nd/2.5/ 


\title{
Improving Competitive Positioning through Complementary Organisational Resources
}

\author{
Author 1 Name: Professor Neil F. Doherty \\ Department: The School of Business \& Economics \\ University/Institution: Loughborough University \\ Town/City: Loughborough \\ State (US only): \\ Country: United Kingdom
}

\section{Author 2 Name: Dr Mark Terry}

Department: The School of Business \& Economics

University/Institution: Loughborough University

Town/City: Loughborough

State (US only):

Country: United Kingdom

Corresponding author: Professor Neil Doherty

Corresponding Author's Email: N.F.Doherty@lboro.ac.uk 


\section{Structured Abstract:}

Purpose - In this paper we draw upon resource-based theory to explore the role of existing, complementary organisational resources, in leveraging sustainable improvements in competitive positioning, resulting from information systems initiatives.

Design/Methodology/Approach - A research model has been derived from the literature, which is then used to guide the conduct of a major, integrated quantitative and qualitative survey of managers.

Findings - In this paper, it is shown that improvements in competitive positioning are likely to be more significant and sustainable when a new IS initiative makes an indirect contribution, through the leveraging of complementary organisational resources, rather than stemming directly from the functionality of the IT asset.

Research limitations / implications - The main limitations of this study relate to its use of a 'convenience' sample and a 'single-informant'. However, both these comprises were viewed as being worthwhile, as it gave us the opportunity to conduct a study that was both broad and deep, in terms of the data collected.

Practical implications - We draw out the implications of our empirical study for the management of IT projects, to improve their ability to deliver sustainable improvements in competitive positioning.

Originality / value - This research makes a significant departure from the aggregated, enterpriselevel orientation of prior studies, by focusing upon the process-level impacts of individual IS initiatives.

Key Words: Resource-based View; improved competitive positioning; sustainability; Complementary Resources.

Article Classification: Research 


\subsection{Introduction}

It is widely acknowledged that a considerable amount of time, money, effort and opportunity has been wasted upon IT investments that have either been abandoned, or ultimately failed to deliver any appreciable benefit [Nelson, 2007; Levison, 2009]. There is also an established stream of research to suggest that the root cause of this problem is the failure of project teams to explicitly consider the organisational impacts and implications of a new piece of software and to proactively manage the associated organisational change [Doherty et al, 2012]. Unless clearer insights can be provided into how value is fashioned from the complex and multi-faceted interactions between the functionality of a particular technical artefact and the wide range of organisational processes and resources with which it interacts, then project teams are unlikely to change their behaviour.

The drive to better understand and document the relationship between IT, organisational resources and value has already attracted much scholarly interest. For example, it has long been recognised that sustainable competitive advantage is unlikely to be leveraged directly from any 'IT asset' [Nevo \& Wade, 2010], as it is relatively easy for firms to understand, and then copy their competitors' systems [Melville et al, 2004]. However, it may still be possible to gain a strategic advantage, if the adoption of IT is supported through the deployment of an appropriate portfolio of complementary resources [Powell \& Dent-Micallef, 1997]. The role of complementary IS/IT resources, in leveraging competitive advantages, has already been extensively explored [Bhatt \& Grover, 2005; Liang et al, 2010]. By contrast, the alternative research stream addressing the competitive role of complementary 'organisational resources' [Nevo \& Wade, 2010], has attracted far less attention. Consequently, it is to the latter, under-researched body of research, that we wish to make our contribution, by exploring whether sustainable improvements in competitive positioning are most likely when a new technology's impact is mediated, indirectly, through organisational resources.

The remainder of the paper proceeds as follows. The next section presents a critical review of the literature, from which the study's specific objectives are derived. We then develop a conceptual framework, before presenting a review of the research methods that were applied to collect data with respect to the model. The framework then provides the basis for a mixed, quantitative and qualitative analysis, which is presented in the fifth section, before the study's contributions are critically reviewed, in the final section. 


\subsection{Sustainable improvements in competitive positioning through IT}

This section provides a critical overview of the use of the resource-based view of the firm, in prior studies of IT for improved competitive positioning, before identifying the gaps the literature and the study's research objective.

\subsection{The Resource-based View [RBV]}

Organizations can realize a competitive advantage if they are able to do something, that is valued by their customers, appreciably better than its competitors [Porter \& Millar, 1985]. Unfortunately, such advantages can be eroded over time, as competitors take steps to understand and then replicate the winning formula. In recent years the resource-based view of the firm has attracted many adherents, as it provides a coherent explanation of how any competitive advantage might be sustained. The central tenet of the RBV is that firms compete on the basis of heterogeneously distributed resources that are valuable, rare, inimitable and non-substitutable: firms that were once thought of as being homogenous are now seen to be differentiated through their possession of difficult-to-imitate resources, which are responsible for the observed variability in their financial and operational performance [Ray et al, 2003].

When seeking candidate resources upon which a sustainable competitive advantage might be built, a great deal of interest has fallen upon IT [Porter \& Millar, 1985]. Although the direct impact of IT upon productivity has remained an enduring theme in the literature [e.g. Ravichandran, \& Lertwongsatien, 2005; Liang et al, 2010; Sandulli, 2010], it is now recognised that there are few circumstances in which the IT artefact can deliver a sustainable competitive advantage, in its own right [Galliers, 1993], because IT is now so widely available and relatively easy to replicate. More recent contributions contend that IT can still deliver a sustainable competitive advantage, but only when it is applied in concert with bundles of complementary resources and capabilities [Dehning and Stratopoulos, 2003; Ravichandran \& Lertwongsatien, 2005]. The idea of resource complementarity is neither new, nor limited to the IS / IT domain. It has been argued [Adegbesan, 2009] that resource complementarity is found in all circumstances where 'resource combination leads to the creation of a "surplus" over and above the sum of the amounts of value they could create independently'. The effects of complementary resources are also likely to be more sustainable, as competitors will find them harder to understand and duplicate [Christensen, 2001]. If one shares the current view that sustainable competitive advantage is most likely in circumstances in which the power of IT is leveraged through complementary resources, 
there are still different interpretations with regard to the nature of this relationship. The most well developed school of thought argues that potential of IT can only be exploited if the host organisation possesses a portfolio of unique, technologically-oriented resources/capabilities needed to develop, implement and then support information systems [Dehning and Stratopoulos, 2003; Fink, 2011]. As a result there have been many prior attempts to develop taxonomies of IS/IT-oriented resources, which typically include capabilities such as: IS technical skills; IS development abilities; effective IS management and IS-business partnership building [Bhatt \& Grover, 2005; Doherty \& Terry, 2009].

The alternative school of thought suggests that competitive advantage it most likely to arise from the introduction of new technology if 'complementarities' can be established between the technical artefact and wider organisational capabilities and assets [Park et al, 2012]. We have chosen to follow Nevo and Wade's [2010] terminology, by terming such non-IT resources as 'organisational resources'. Organisational resources are very distinct from the IS/IT resources and capabilities, in that they are only leveraged once the system has been implemented [Melville et al; 2004]. For example, a new system might deliver a more sustainable competitive advantage, if it does this indirectly through the leveraging of preexisting organisational resources such as culture, structure, knowledge and leadership capabilities [Powell \& Dent-Micallef, 1997; Benitez-Amado, 2010].

\subsection{Critique of Literature and Research Objective}

Although there is already an extensive literature relating to the application of the RBV in the context of IT, it is still possible to identify a number of fertile areas in which important contributions can be made regarding the role of complementary resources in leveraging value from IT. For example, most prior research has focussed upon the role of IS / IT capabilities, rather than organisational resources, in facilitating competitive advantage [Table 1; column 4]. Moreover, prior studies of the competitive impacts of IS investments [Table 1; columns 3 \& 5] have typically utilized enterprise level measures of performance, from which it is difficult to isolate the impacts of specific IT initiatives, upon competitive positioning [Ray et al, 2003]. Finally, most prior studies have assessed any performance improvements over a fixed three year period [Table 1; columns $6 \&$ 7], rather than determining the absolute duration of any improvements in competitive positioning.

Having identified a number of dominant themes, recurring in the existing literature, it was possible to define the space in which we wanted to situate our novel contribution. More specifically, the following research goal was defined: to determine the extent to which the 
level of sustained improved competitive positioning, arising from IT, will be greater, when it arises indirectly, through the leveraging of complementary organisational resources, rather than directly from the implementation of an IT Asset. However, in addressing this objective, this study makes a significant departure from the highly aggregated, enterprise-level orientation of prior studies by measuring the actual duration of the competitive impacts of individual IS initiatives, at the process level. In the following section we present the research model through which this research goal was explicitly tested.

\subsection{Research Framework}

We wanted to explore the extent to which an organization's ability to initially leverage, and then sustain, an improved competitive positioning from the introduction of an 'IS initiative' is directly related to the IT asset's functionality, or whether the impact of the technology is indirectly 'mediated' [Lee et al, 2008] through organisational resources. A broad overview of this research question, and its constituent constructs, is presented in figure 1 , whilst a more detailed discussion of how each construct was operationalised is presented below:

- IS Initiative: Informants were asked to identify a specific 'IS initiative', with which they were familiar, that had resulted in an improvement to their organisation's competitive positioning. The 'IS initiative' could either be either a completely new IS implementation, or a major enhancement to an existing system. Informants were asked to name, and briefly describe, their chosen 'IS initiative', but this information didn't play any role in the statistical analysis. However, it was envisaged that the simple act of providing an explicit description would ensure that the respondents were clearly focused upon a single strategic initiative before they attempted to answer the remaining questions.

- Directness of sustained improved competitive positioning: The directness of the sustainability of ICP variable was designed to measure the source of competitive positioning across a range of common business processes. To this end, a taxonomy of eleven common processes was developed [see table 2], based upon a very common process model [APQC, 2006]. For each of the eleven processes, a semantic differential scale was used to determine the extent to which the sustainability of any improvements in competitive positioning were leveraged either directly through the agency of the IT artefact, or indirectly, through the mediating role of organisational resources [Lee et al, 2008].

- Sustained Improved Competitive Positioning [SICP]: This study also sought to break new ground by focusing on the degree of improved competitive positioning, leveraged from an IS initiative, rather than focusing solely on situations in which an 
outright competitive advantage had been realized. The framework had, therefore, been designed to model the extent to which the competitive positioning of each process had been improved through the introduction of the specified technology. Respondents were also asked state the duration, in years, that this improvement had been sustained. It was therefore possible to create an overall measure of SICP by calculating the product of the degree and duration of ICP. A high number signifies a substantial, long-lasting improvement in competitive positioning, whereas, a small number is indicative of a modest, short-lived impact.

It was envisaged that the research framework, as described above, would be used initially to collect some quantitative data, and undertake some provisional statistical analysis, before using it as the mechanism for collecting more detailed, qualitative data.

\subsection{Research Methods}

We chose to adopt both quantitative and qualitative data collection approaches, to build a richer and deeper picture of the phenomenon under investigation [Gable, 1994]. In so doing, it both increased the validity of findings and helped to explain diverging results. The aim of the remainder of this section is to review how a questionnaire was designed, validated and executed, before describing the methods employed for the follow-up qualitative study.

\subsection{Quantitative study - design and execution}

As the focus of this study was very different from previous questionnaire-based contributions, it was not possible to adapt specific questions and item measures from the existing literature. A completely new questionnaire was, therefore, created to collect detailed data about the competitive impacts and implications of each respondent's chosen IS initiative, on each of the eleven business processes, included in our model [see table 2]. Once this draft questionnaire had been created, it was necessary to validate it through a phased pre-testing regime. Firstly, it was reviewed by twelve experienced IS researchers and academics, and after some modifications, it was then re-tested with a different set of seven IS academics. It was given a final test with ten practicing managers, all of whom were experienced users of information systems. The pre-tests were very useful, as they resulted in a number of significant enhancements being made to the structure of the survey and the wording of specific questions. Having refined the questionnaire, a pilot study exercise, of 57 managers, was also undertaken, which yielded 7 complete responses. Although the number of responses was quite modest, it still provided valuable insights into the likely response rate and analytical implications for the full survey. 


\subsection{Quantitative study - targeting and execution}

As we were primarily seeking insights into the competitive impacts of IT, it was recognized that the most appropriate group of individuals to target would be managers who had been heavily involved in major information systems initiatives. Moreover, it was decided to target only large [>250 employees], private sector organizations, as it was felt that they were more likely to have the more sophisticated process architecture reflected in the research model, and it was also envisaged that public sector organizations were unlikely to have the required competitive focus to their operations. Given that we sought to recruit participants who would initially complete a highly complex and commercially sensitive survey instrument, and then be prepared to participate in fairly lengthy interviews, we recognized that there was little likelihood of satisfying these objectives, from a completely random sample. Consequently, we decided to a 'convenience sampling' approach, which is becoming increasingly common in similar research contexts, [Tarafdar \& Gordon, 2007; Mohdzain \& Ward, 2007], and a sampling frame was constructed, of managers with whom the researchers' UK-based university had professional ties. In particular, we targeted the managers of undergraduate students, on their placement year, and practicing managers who had graduated from executive development or executive MBAs programs. Ultimately, a total of 109 valid responses were received from the 839 questionnaires successfully e-mailed out, representing a response rate of $13 \%$. Whilst this response rate is perhaps a little disappointing, it is not surprising given the commercially sensitive nature of questions relating to an organization's competitive positioning, and the complexity of the research instrument.

\subsection{Qualitative study - design, validation and targeting}

By applying a qualitative lens, it was envisaged that as well as corroborating the results of the statistical analysis, it would be possible to generate far richer and deeper insights, which would allow us to interpret and elaborate the results of our quantitative study [Strauss and Corbin, 2007]. Consequently, having completed the quantitative study and reflected upon its results, a script of interview questions was developed. The script was explicitly designed to complement and enrich the statistical findings by probing specific aspects of our results that required further clarification or interpretation. This interview script was pre-tested with fellow academics to ensure its clarity and relevance, and then pilot tested with five appropriate managers. The targeting strategy for the qualitative study was relatively straightforward as every respondent to the quantitative study had been asked to tick a box if they would be prepared to participate in a follow-up interview. In total 36 respondents volunteered to 
participate in the interviews, each of which lasted between 45 and 90 minutes. Each interview was tape recorded and then fully transcribed, and a sample of these was returned to the interviewees to ensure that the process was accurate and free from bias. The interview transcriptions were then imported in a rich text format to NVIVO, which facilitated the coding, editing annotation and analysis of the transcripts, and using 'tree nodes' were used to group related themes together. Having encoded the data, the 'variable-oriented' form of 'cross-case analysis' [Miles \& Huberman, 1994] was applied, to identify richer patterns, with regard to key constructs, and the relationships between them.

\subsection{Research Findings}

This section presents the research results, firstly with respect to the preliminary, statistical analysis of the survey data, followed by a far deeper qualitative analysis of the interview data.

\subsection{Analysis of Quantitative Data}

When choosing the statistical tool, with which to conduct the quantitative analysis, the primary selection criteria was that it should be able to cope with high levels of incomplete data: respondents would only provide data for the specific processes that had been impacted by a particular initiative, and all the unaffected processes would be ignored. For example, if a respondent perceived that their chosen system had only exerted a competitive impact on three out of our eleven business processes, then the questions with regard to the remaining eight processes would intentionally be left blank. Consequently, we chose to adopt correlation analysis as it could be used to explore the complex relationships between the degree to which impacts are direct or indirect and the resultant process-level improvements in competitive positioning, even if there were significant amounts of missing data. The results of a correlation analysis, between the directness of the impact and the resulting level of sustained improved competitive positioning, are presented in table 2.

From an examination of the data in table 2 it can be seen that the really interesting story to emerge from this analysis, is not at the level of individual business processes, but the differences that can be seen between the two different classes of process.. More specifically, in five out of the six 'operational' processes there is a significant correlation, at the 0.05 level, or above, between the directness of the IS-enhancement's contribution and the resultant level of sustained improved competitive positioning, whilst there is only one 'management and support' process for which a significant relationship has been found. It is important to 
note that in all cases in which there is a significant association, the correlation statistic is always negative, meaning that higher levels of sustained improved competitive positioning, are more commonly seen in situations in which the impacts of an IS enhancement are engendered indirectly, through the mediation of organisational and human resources, rather than directly, through the technology's functionality. However, it is important to reflect upon these results, rather more carefully, to understand exactly what they are saying.

It can also be seen, from table 2, that both the operational and the management processes appear to have broadly similar levels of potential to deliver a sustainable improvement in competitive positioning: average values range from 4.5 to 6.9 for both classes of process [see column 2]. Moreover, processes of both classes, can be competitively affected by technology, both directly and indirectly: average values range from approximately $46 \%$ to $58 \%$, for both classes of process [see column 3]. Consequently, it is not possible to make any broad generalizations about whether the adoption of IT in support of operational or management processes is more likely to be a source of improved competitive positioning. Indeed, the results of our analysis would suggest that IT has the potential to deliver positive competitive impacts when harnessed to any common business process. In a similar vein, there are no clear distinctions to be seen, between operational or management processes, when it comes to whether technology typically makes a direct or indirect impact. However, the findings of our study do suggest that for the majority of the 'operational' processes, high levels of sustainable improvements in competitive positioning are more likely to be realised if the affects of the technology are leveraged indirectly, through the intermediation of human resources.

From our interpretation of the results, it is possible to make the broad generalisation that when organisations seek to apply IT, in support of their core 'operational' processes, then a sustainable improvement in competitive positioning is more likely to be attained, if its competitive affects are leveraged indirectly, through the intermediation of human resources. Indeed, it is only when IT is used to support the 'marketing and selling of products or services' that this generalisation does not appear to hold true. In sharp contrast to the operational processes, there was no strong evidence to suggest that the intervention of human or other organisational resources, was typically needed to leverage the competitive impacts of IT, when it is applied to the management and support processes. Indeed, there is only one management process - 'developing vision and strategy' - for which any significant association has been found. 


\subsection{Analysis of Qualitative Data}

Whilst the statistical analysis highlighted some interesting associations between the directness of impact and the degree / sustainability of any improvement in competitive positioning, particularly for the 'operational' processes, it was unable to present any richer interpretations of the nature of these relationships. To help make sense of the statistical analysis, the interview data was used to provide deeper insights into:

- the resource-based mechanisms through which the improved competitive positioning had been achieved and sustained;

- the relative importance of IT resources and organisational resources.

Moreover, as correlation is a relatively weak form of statistical analysis, the follow-up qualitative study was used to corroborate, through 'triangulation' [Bryman, 2006], the results of the correlation analysis, and in so doing, it has greatly increased our confidence in their validity.

From the analysis of the qualitative data a number of important patterns emerged. The majority of the interviewees, who reported improvements to their operational processes, were typically basing their responses upon the competitive impacts of common packages such as ERP, EPOS, CAD or CRM systems. When interviewees were asked to describe the direct competitive impacts that could be leveraged through the implementation of such systems, then phrases such as: 'efficiency gains', 'cost savings', 'paperless processes' and 'head count reductions' were often used. For example, one respondent [\#4] described how the introduction of a CRM system, within his bank, had directly improved the efficiency of the process of 'delivering products and services', by providing personnel with all the information they needed to complete a transaction, in an easy to assimilate form. As he commented, employees can: 'now spend more time with the customer, rather than wasting time looking for the information they need'. However, such competitive impacts were typically perceived to be modest and short-lived, when they had been leveraged directly from the functionality of the technology. For example, another interviewee [\#28] described a system, for improving the efficiency of the loan approval process, within his bank. As he noted, $80 \%$ of the improved competitive positioning for the 'customer service' process could be directly attributed to the IS-enhancement itself, as opposed to the other $20 \%$, which was achieved indirectly. As he went on to note: I think the majority of the 1-2 year came down to the duration it took our competitors to understand the system, and implement their own versions'. Indeed, the system was soon imitated by the majority of bank's competitors, to the extent that 'it became an industry standard quite quickly'. 
There were also many counter examples of where improvements to the competitive positioning, of operational processes, had been gained primarily through the indirect impacts of an IS initiative. In such cases, respondents were typically focussing upon the qualities of their existing organisational resources, and using phrases such as: 'excellent skills base', 'unique culture', and "high calibre workforce'. For example, one interviewee [\#30] described how the ERP-enabled improvements to his organisation's 'customer services' process, which were sustained over a four year period, had been primarily leveraged through the high quality of the organisation's personnel. As he went on to comment: 'even if you implemented the best computer system in the world, to support the work of ineffective staff, the levels of customer service would still be poor'. There were also many insights into why improvements in competitive positioning, achieved through the indirect effects of a new technology, were typically perceived to be more significant and sustainable For example, one interviewee's organisation [\#1] acted as the central purchasing function for a large consortium of independent retailers, and the competitive advantage was initially triggered by the introduction of centrally-coordinated EPOS systems across the complete consortium of retailers. The system allowed the organisation to collate real-time, sales data, from which highly accurate bulk purchasing decisions could be made. As the interviewee noted very little of the improved competitive positioning for the process of 'acquiring and storing inputs required for products or services' could be directly attributed to the IS-enhancement itself. As he noted, whilst the distributed EPOS system proved to be an important enabler and catalyst, the improved competitive positioning was achieved primarily through the company's 'unique organisational structure and its purchasing power', and that isn't something that competitors could 'understand or replicate easily'.

Having established that, particularly in the context of operational processes, sustainable improvements in competitive positioning are more likely to be indirectly leveraged through organisational resources, than directly through the functionality of the IT asset, it is important to briefly consider a subsidiary question: do complementary organisational resources play a more significant role than IS/IT resources, in the leveraging of a sustainable improvement in competitive positioning? Although this question was not explicitly addressed through our statistical analysis, it was an issue that was addressed during the interview sessions. It is important to note that our interview respondents readily acknowledged the importance of complementary IS/IT resources - such as IS planning and change management, IS technical skills and IS-business partnerships [Wade \& Hulland, 2004]. Indeed, there was much support for the argument that improved competitive positioning is dependent upon a portfolio of such IS/IT resources, as the follow quotes indicate: 
- 'I would say the resources I have mentioned played an important part in the success of the system and it probably would not have succeeded without them... we probably wouldn't have identified the right system or been able to link it throughout the organisation' [\#4];

- 'They [the IS/IT resources] really enabled us to implement new functionality into the system quicker and more cost effectively than our competitors [\#12];

- 'The IS/IT resources mentioned were essential in enabling us to gain the advantages we did from the system... You can't simply implement a system and expect it to give you an advantage' [\#23].

Although there was significant support for the proposition that complementary IS/IT resources also play an important role in leveraging improved competitive positioning from an IT asset, when asked whether it was the organisational resources or the IS/IT resources that generally played the more important role in the delivery of sustained improvements in competitive positioning, the message was clear: organisational resources are more important than IS / IT resources for delivering a sustainable improvement in competitive positioning, as explained in the following quotes:

- I'd say it came down to the fact that our competitors didn't really have to copy our IS IIT resources to be able to implement the system, but to gain the ongoing advantage, they would have to replicate our culture and organisational flexibility [organisational resources], which would take a great deal of time' [\#30];

- 'My feeling is that anyone could replicate the actual piece of software or near enough so that wasn't really having all that much of a contribution to sustainability. The indirect affect is what our competitors would find very difficult to replicate' [\#1].

In conclusion, the results of the qualitative study provided important support to the central thesis of this study, by confirming that any improvements in competitive positioning derived indirectly through the mediation of organisational resources are likely to be stronger and last longer, than direct impacts, particularly in the context of operational processes. Furthermore, the qualitative study has helped to explain the results of the statistical analysis, by demonstrating why the mediating effects of organisational resources tend to be more important: their effects tend to be less obvious and consequently they are far more difficult for a competitor to copy. Finally, it has been demonstrated that organisational resources are perceived to be more important levers of competitive advantage than IS / IT resources, once 
more because they tend to be deeply rooted within the organisation, and less easy to replicate.

\subsection{Discussion \& Conclusions}

As it becomes easier for organisations to quickly replicate their competitors' successful systems, opportunities for IT investments to directly deliver sustainable improvements in competitive positioning are becoming fewer [Hailpern and Tarr, 2006]. The hunt is now on, therefore, to find alternative ways in which IT can deliver long-term value. Moreover, it has also been argued that the strategic outcomes of IS/IT investments should be measured at the intermediate process level, as it is only at this level that IT enabled contributions can be reliably assessed [Barua, et al., 1995; Ray et al., 2004]. This leaves the results of the vast majority of existing competitive value studies, which have been conducted at the enterprise level, open to question. Against this backdrop, our study makes an important contribution by adopting the novel approach of studying the competitive effects of individual IS initiatives at the process level, and by measuring the absolute duration for which these impacts were sustained. Moreover in providing both quantitative and qualitative evidence, it has been possible to both 'triangulate' and 'elaborate' the results of this study [Bryman, 2006].

It has been widely argued that the effective leveraging of complementary 'organisational resources' is critical for the realisation of sustainable improvements in competitive positioning form technology investments [Dehning and Stratopoulos, 2003; Ravichandran \& Lertwongsatien, 2005]. By their very nature, complementary organisational resources can be difficult to understand and articulate, and consequently, IT-based competitive advantages that have been leveraged through such resources, are extremely difficult to replicate [Nevo \& Wade's, 2010]. However, by adopting a process-level approach, this study makes an important contribution, by helping to elaborate and qualify this widely held belief. This study does present important new empirical evidence that IT assets are more likely to deliver higher levels of sustained improved competitive positioning, if their effects are leveraged indirectly through organisational resources, rather than being exerted directly, but only when applied in the context of core 'operational' processes. By contrast, for the majority of management and support processes, there are less clear relationships between the attainment of sustainable improvements in competitive positioning, and the directness or indirectness of the mechanism through which they were achieved. 
The process-level results of our qualitative analysis also provide important new insights into why human and organisational resources are needed to leverage IT, when it has been applied to core operational processes. The findings indicate that well designed management information could enhance the performance of personnel, and particularly managers, either directly or indirectly. The direct impacts tended to be in cases in which a new system simply helped to collate many disparate, but existing, sources of information, and whilst such applications facilitated important improvements in the productivity of personnel, there were no other significant sources of added value, to the underlying process. By contrast, the more sustainable, indirect impacts came about when completely new sources of information or knowledge were made available to highly skilled professionals, which allowed them to perform at an even higher level. In these cases, because the competitive advantage is coming predominantly through the leveraging of the skills and capabilities of the organisation's human resources, they are far harder to understand, and ultimately imitate.

Although a range of prior studies [Dehning and Stratopoulos, 2003; Ravichandran \& Lertwongsatien, 2005] have argued that attaining a competitive advantage from IT is dependent upon the effective deployment of IS/IT resources and capabilities, this study makes a further contribution by providing an initial analysis of the relative importance of organisational resources and IS/IT resources. The qualitative element of our research provides important new insights into the complementary roles played by these two different types of resources. The IS/IT resources are primarily deployed, during the systems planning, development and implementation periods, to help deliver a more effective IT artefact that can provide the functionality and informational outputs that an organisation needs to successfully compete. By contrast, the organisational resources become more important, once the system is operational, to ensure that the system's functionality and informational outputs are being used to good effect, and as our study demonstrated it is these organisational resources that are perceived to be the most important in delivering sustainable improvements in competitive positioning.

Our findings offer a number of important insights to managers seeking to realise more value from their investments in IT. For example, in the context of operational systems, the results of this study suggest that success will be more likely if organisations are able to identify how IT can be used to effectively leverage their existing resources and capabilities. To this end, senior managers will need to pay more attention to the explicit integration of their IS / IT and corporate strategies, and the development of capabilities that facilitate IT-organisational integration. The findings also underline the importance of managers critically reviewing the 
effectiveness of their existing industrial processes, when implementing IT, to identify opportunities for process improvement. As our study has highlighted the critical role of the human resource, in leveraging value from IT initiatives, it is also important that all managers recognise that their investments will only deliver value, if they proactively address the human factor implications.

Research within complex organizational settings will invariably contain a number of inherent limitations, as compromises and trade-offs are always necessary. For example, compromises were made with respect to the generalizability of the results, as we had to adopt a 'convenience' sample, to enable us to engage respondents who would be prepared to both complete a complex questionnaire, and then participate in a lengthy interview. Moreover, as this study only targeted large, private sector organisations, the implications of our results may not be applicable to other types of organisation. Other limitations, of this study, relate to the use of a 'single-informant', and the use of some 'single item' measures in the questionnaire. Consequently, although this study provides many interesting and novel insights, there is now a pressing need for follow-up studies, which employ different analytical techniques, target alternative populations, and employ alternative theoretical perspectives, such as Agency Theory. 


\section{References}

1. Adegbesan, A. J. (2009). "On the origins of competitive advantage: Strategic factor markets and heterogeneous resource complementarity," Academy of Management Review, 34, pp. 463-475.

2. American Productivity and Quality Center (2006), Process Classification Framework, APQC, Houston, TX, p. 16, available at: www.apqc.org.

3. Barua, A., Kriebel, C. H., \& Mukhopadhyay, T. (1995) "Information technologies and business value: An analytic and empirical investigation", Information Systems Research, 6 (1), pp. 324.

4. Benitez-Amado, J., Llorens-Montes, F.J. and Perez-Arostegui, M.N. (2010), "Information technology-enabled intrapreneurship culture and firm performance", Industrial Management \& Data Systems, 110 (4), pp. 550-66.

5. Bhatt, G. D. \& Grover, V., (2005) "Types of Information Technology Capabilities \& their Role in Competitive Advantage: an Empirical Study", Journal of Management Information Systems, 22 (2), pp. 253-277.

6. Bryman, A. (2006) "Integrating quantitative and qualitative research: how is it done?", Qualitative Research, 6 (1), pp. 97 - 113.

7. Christensen CM. (2001) "The past and future of competitive advantage". MIT Sloan Management Review 42: 105-109.

8. Dehning, B. \& Stratopoulos, T. (2003) Determinants of sustainable competitive advantage due to IT-Enabled strategy, Journal of Strategic Information Systems 12, 1, 7-28.

9. Doherty, NF, Ashurst, C, Peppard, J (2012) "Factors Affecting the Successful Realisation of Benefits from Systems Development Projects: Findings from Three Case Studies", Journal of Information Technology, 27 (1), pp.1-16

10. Doherty, N.F. and Terry, M., (2009) "The Role of IS Capabilities in Delivering Sustainable Improvements to Competitive Positioning", Journal of Strategic Information Systems, 18, pp 100-116,

11. Fink, L. (2011) "How do IT capabilities create strategic value? Toward greater integration of insights from reductionistic and holistic approaches", European Journal of Information Systems, 20, pp. 16-33.

12. Gable, G.G. (1994) "Integrating Case Study and Survey Research Methods: An Example in Information Systems," European Journal of Information Systems, 3 (2), pp.112-126.

13. Galliers, R.D., (1993), "IT strategies: beyond competitive advantage", Journal of Strategic Information Systems 2, 4, 283-291.

14. Hailpern, B. and Tarr, P. (2006) "Model-driven development: The good, the bad, and the ugly". IBM Systems Journal, 45(3), pp. 451-461.

15. Lee, S.M., Kim, K., Paulson, P. and Park, H. (2008), "Developing a socio-technical framework for business-IT alignment", Industrial Management \& Data Systems, 108 (9), pp. 1167-81.

16. Levinson, M. (2009) "Recession Causes Rising IT Project Failure Rates", ClO Magazine, 18 / June / 2009. 
17. Liang, T.-P., You, J.-J. and Liu, C.-C. (2010), "A resource-based perspective on information technology and firm performance: a meta analysis", Industrial Management \& Data, Systems, Vol. 110 No. 8, pp. $1138-58$

18. Melville, N., Kraemer, K. \& Gurbaxani, V. (2004) "Review: IT \& Organisational Performance: An Integrative Model of IT Business Value", MIS Quarterly, 28 (2), pp. 283-322.

19. Mohdzain, M. B. \& Ward, J. M. (2007) A study of subsidiaries' views of IS strategic planning in multinational organizations", Journal of Strategic Information Systems, 16, 324-352.

20. Nelson, R.R. (2007) "IT project management: infamous failures, classic mistakes, and best practices", MIS Quarterly Executive, 6/2 pp. 67-78.

21. Nevo, S., \& Wade, M. R. (2010). "The formation and value of IT-enabled resources: Antecedents and consequences of synergistic relationships", MIS Quarterly, 34 (1) 163-183.

22. Ordanini, A. and Rubera, G. (2010), "How does the application of an IT service innovation affect firm performance? A theoretical framework and empirical analysis on e-commerce", Information \& Management, 47 (1), pp. 60

23. Park, Y.W., Fujimoto, T., and Hong, P. (2012). "Product Architecture, Organizational Capabilities and IT Integration For Competitive Advantage". International Journal of Information Management, 35 (2), pp. 479-488.

24. Powell, T.C. \& Dent-Micallef, A. (1997) IT as competitive advantage: The role of human, business, \& technology resources, Strategic Management Journal 18, 5, 375-405.

25. Ravichandran, T. \& Lertwongsatien, C. (2005), Effect of Information Systems Resources \& Capabilities on Firm Performance: A Resource-based Perspective, Journal of Management Information Systems, 21 (4), pp. 237-276.

26. Ray, G., Barney, J.B. \& Muhanna, W.A. (2003) "Capabilities, Business Processes, \& Competitive Advantage: Choosing the Dependent Variable in Empirical Tests of the Resource-Based View", Strategic Management Journal 25, 1, 23-37.

27. Sandulli, F., Fernandez-Menéndez, J., Rodriguez-Duarte, A., \& Lopez-Sanchez, J. (2010) "The productivity payoff of information technology in multimarket SMEs". Small Business Economics, 1-19.

28. Strauss AL and Corbin J (2007) Basics of qualitative research: Techniques and procedures for developing grounded theory. Sage: Newbury Park, CA.

29. Tarafdar, M. \& Gordon, S. R. (2007), "Understanding the influence of IS competencies on process innovation: A resource-based view", Journal of Strategic Information Systems, 16, 353-392.

30. Wade, M., \& Hulland, J. (2004) "The resource-based view \& information systems research: Review, extension, \& suggestions for further research", MIS Quarterly, 28, 1, 107-142.

31. Zhang, M., Sarker, S. and Sarker, S. (2008), "Unpacking the effect of IT capability on the performance of export-focused SMEs: a report from China", Information Systems Journal, 18 (4), pp. 357-80. 
Table 1: Prior RBV studies that examine the impact of resources upon competitive positioning

\begin{tabular}{|c|c|c|c|c|c|c|}
\hline Authors & Date & $\begin{array}{l}\text { Unit of } \\
\text { Analysis }\end{array}$ & $\begin{array}{l}\text { Independent } \\
\text { Variable }\end{array}$ & Dependent Variable[s] & $\begin{array}{l}\text { Competitive advantage } \\
\text { assessed? }\end{array}$ & $\begin{array}{l}\text { Duration of } \\
\text { advantage I } \\
\text { assessed? }\end{array}$ \\
\hline $\begin{array}{l}\text { Powell \& Dent- } \\
\text { Micallef }\end{array}$ & 1997 & The firm & $\begin{array}{l}\text { Human, business \& } \\
\text { technology resources }\end{array}$ & IT \& overall company performance & $\begin{array}{l}\text { Yes - comparison with } \\
\text { competitors over a three year } \\
\text { period. }\end{array}$ & No \\
\hline $\begin{array}{l}\text { Dehning \& } \\
\text { Stratopoulos }\end{array}$ & 2003 & The firm & IT capabilities & Return on Assets & $\begin{array}{l}\text { Yes - comparison with direct } \\
\text { competitors. }\end{array}$ & Yes \\
\hline $\begin{array}{l}\text { Ravichandran \& } \\
\text { Lertwongsatien }\end{array}$ & 2005 & The firm & $\begin{array}{l}\text { IS / IT \& } \\
\text { organisational } \\
\text { capabilities }\end{array}$ & $\begin{array}{l}\text { Profitability, productivity, new product } \\
\text { launches }\end{array}$ & $\begin{array}{l}\text { Yes - comparison with } \\
\text { competitors over a three year } \\
\text { period. }\end{array}$ & No \\
\hline Bhatt \& Grover & 2005 & The firm & IT capabilities & Sales growth and financial performance * & $\begin{array}{l}\text { Yes - comparison with } \\
\text { competitors over a three year } \\
\text { period. }\end{array}$ & No \\
\hline Lin & 2007 & The firm & IT capabilities & $\begin{array}{l}\text { ROE, MVA, EVA, Tobin's Q, market -to -book } \\
\text { ratio }\end{array}$ & $\begin{array}{l}\text { No - absolute measures of } \\
\text { firm performance used }\end{array}$ & No \\
\hline $\begin{array}{l}\text { Zhang, Sarker \& } \\
\text { Sarker }\end{array}$ & 2008 & The firm & IT capabilities & $\begin{array}{l}\text { International performance of export-focused } \\
\text { Chinese SMEs }\end{array}$ & $\begin{array}{l}\text { No - absolute measures of } \\
\text { firm performance used }\end{array}$ & No \\
\hline $\begin{array}{l}\text { Ordanini \& } \\
\text { Rubera (2010), }\end{array}$ & 2010 & The firm & $\begin{array}{l}\text { IS / IT \& } \\
\text { organisational } \\
\text { capabilities }\end{array}$ & $\begin{array}{l}\text { return on assets (ROA), return on sales } \\
\text { (ROS) and operational income. }\end{array}$ & $\begin{array}{l}\text { No - absolute measures of } \\
\text { firm performance used }\end{array}$ & No \\
\hline
\end{tabular}


Figure 1: Research framework

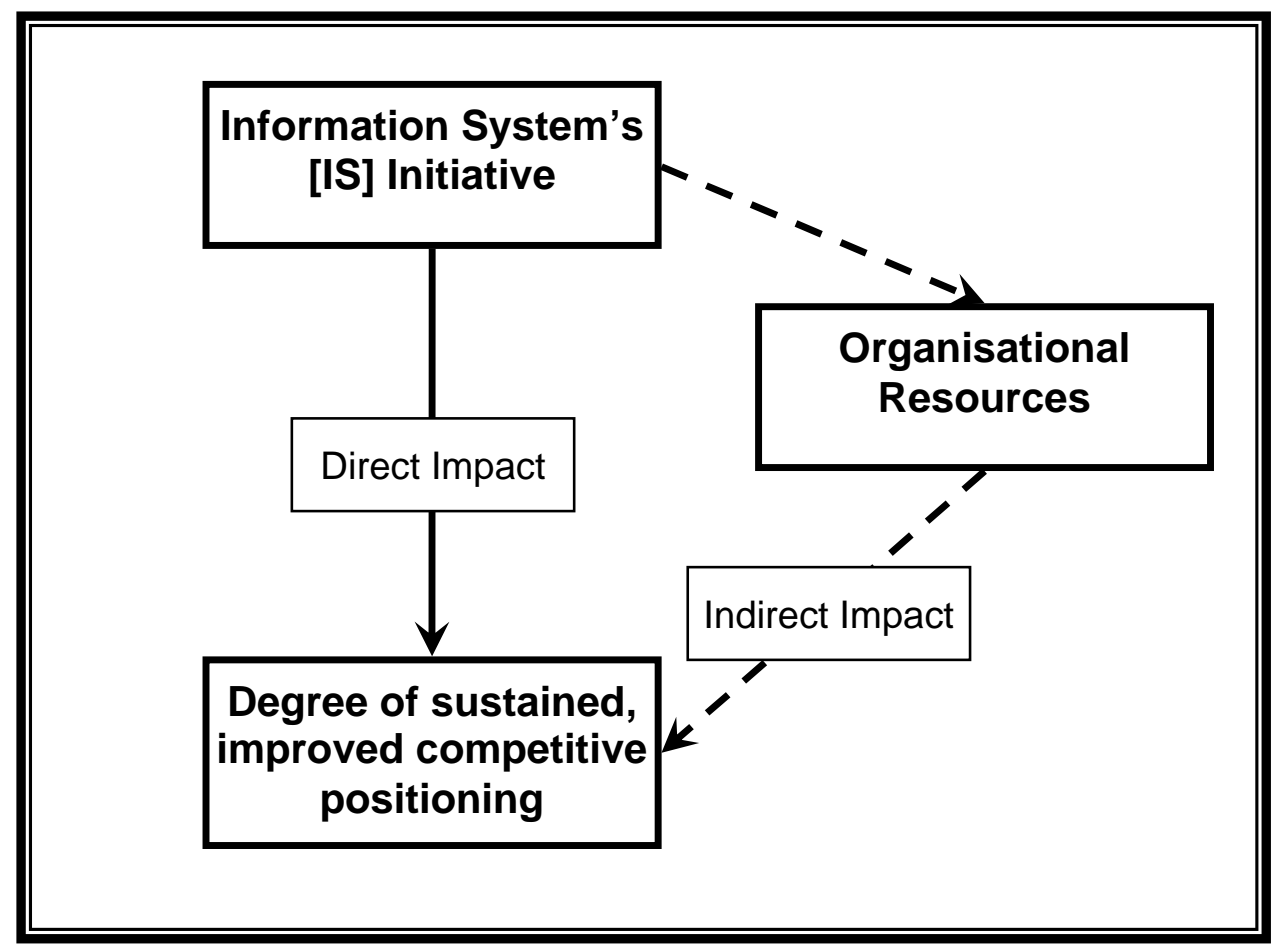

Table 2: Relationship between directness of impact and the degree of SICP

\begin{tabular}{|c|c|c|c|c|}
\hline Process SICP & $\begin{array}{c}\text { Average degree } \\
\text { of SICP }\end{array}$ & $\begin{array}{l}\text { Average directness } \\
\text { of IT's impact }\end{array}$ & $\begin{array}{l}\text { Pearson } \\
\text { correlation }\end{array}$ & $\begin{array}{l}\text { Process } \\
\text { Class }\end{array}$ \\
\hline $\begin{array}{l}\text { Designing and developing } \\
\text { products or services }\end{array}$ & 6.5 & $52.3 \%$ & $-.315^{\star}$ & Operational \\
\hline $\begin{array}{l}\text { Acquiring and storing input } \\
\text { required for products or services }\end{array}$ & 6.9 & $51.7 \%$ & $-.597 * *$ & Operational \\
\hline $\begin{array}{l}\text { Transforming acquired inputs } \\
\text { into a product or service }\end{array}$ & 6.3 & $53.3 \%$ & $-.524^{\star *}$ & Operational \\
\hline $\begin{array}{l}\text { Marketing and selling products } \\
\text { or services }\end{array}$ & 4.5 & $58.2 \%$ & -.051 & Operational \\
\hline Delivering products or services & 5.4 & $52.8 \%$ & $-.342^{*}$ & Operational \\
\hline Customer service & 5.8 & $45.7 \%$ & $-.255^{\star}$ & Operational \\
\hline Developing vision and strategy & 4.5 & $46.7 \%$ & $-.347^{*}$ & Management \\
\hline $\begin{array}{l}\text { Developing and managing } \\
\text { human capital }\end{array}$ & 6.9 & $46.3 \%$ & -.067 & Management \\
\hline $\begin{array}{l}\text { Managing information } \\
\text { technology and knowledge }\end{array}$ & 6.3 & $58.0 \%$ & -.158 & Management \\
\hline Managing financial resources & 6.4 & $51.9 \%$ & -.185 & Management \\
\hline Managing external relationships & 4.9 & $55.4 \%$ & .058 & Management \\
\hline
\end{tabular}

** Significant at the 0.01 level; * Significant at the 0.05 level 